\title{
BIOTECNOLOGÍAS Y ÉTICA: CON ESPECIAL REFERENCIA A LA INGENIERÍA GENÉTICA
}

\author{
BIOTECHNOLOGIES AND ETHICS: WITH SPECIAL \\ REFERENCE TO GENETIC ENGINEERING
}

FERNANDO LOLAS STEPKE1

\section{RESUMEN}

Este artículo examina las consecuencias éticas y los presupuestos valóricos de las tecnologías de la vida, especialmente aquellas que la manipulan, estudiando el poder de soberanía y el poder disciplinario que ellas evocan y convocan. A propósito de su estatuto disciplinario, desarrolla nociones relacionadas con la innovación tecnológica y sus estadios antes de convertirse sus productos en parte de la vida social. Quedan planteadas preguntas relativas a la distinción entre invención e innovación, que la tecnología genética parece difuminar, y al necesario balance entre progreso tecnológico y humanidad que debe presidir los debates bioéticos.

Palabras clave: Biotecnología, bioética, innovación tecnológica.

\section{ABSTRACT}

This paper examines ethical consequences and value assumptions of life technologies, particularly those that manipulate life, studying the power of sovereignty and the disciplinary power that they evoke and convene. Notions related to technological innovation and its stages are developed in relation to their disciplinary status before and during their transit to social products. Questions related to the distinction between invention and innovation, relativized by genetic technologies, are posed, along with those related to the balance between humanity and technological progress which should be present in bioethical debates.

Keywords: Biotechnology, bioethics, technological innovation.

Recibido: 06.09.2009. Aprobado: 12.03.2010.

${ }^{1}$ Profesor Universidad de Chile. Santiago, Chile. Director Programa de Bioética, Organización Panamericana de la Salud/Organización Mundial de la Salud. E-mail: lolasf@chiops-oms.org 


\section{BIOTECNOLOGÍAS: ANTIGUAS Y MODERNAS}

$\mathrm{U}$

NA tecnología es una técnica, o un conjunto de técnicas, más un contexto de aplicación y justificación. Un logos da razón de su re levancia. Biotecnologías pueden llamarse aquellas tecnologías que manipulan lo vivo con algún propósito: utilitario, estético, económico.

Cabe distinguir diversas formas históricas.

Las clásicas o antiguas son empíricas, sin teorías que expliquen o anticipen su mecanismo o eficacia, utilitarias y fruto más del descubrimiento (azaroso o no) que de la invención. Desde la fabricación del pan hasta la hibridación de animales y plantas, estas biotecnologías no alteran en forma directa la naturaleza. Usan sus recursos con habilidad e ingenio. No manipulan, sólo reutilizan. Los intentos eugenésicos del pasado pueden considerarse "biotecnológicos" por implicar intervenciones sobre la reproducción humana para lograr efectos en poblaciones y personas. No manipularon directamente el genoma. La denominada "higiene racial" consistió en seleccionar, reproducir o eliminar individuos por sus rasgos fenotípicos y no por un conocimiento del material genético. Estas tecnologías deben enjuiciarse no por su eficacia sino por sus fines y los medios, lícitos o ilícitos, que sus proponentes utilizaron.

En las biotecnologías modernas las intervenciones tienen fundamento científico, predicción de eficacia y la posibilidad de afectar transformativamente (esto es, alterar) mecanismos vitales, especialmente en el genoma. La producción de alimentos transgénicos o la terapia génica son ejemplos. La posibilidad de efectos no deseados y la irreversibilidad de las intervenciones son materia de debate. Se lleva al límite la intervención tecnocrática. Viejos sueños como la salud perfecta o la longevidad infinita parecen posibles. Puede hablarse de una "medicina del deseo" basada en la biotecnología, que ofrece panaceas y curaciones milagrosas. Esta libido sciendi asociada a la idea del progreso infinito distingue la biotecnología contemporánea de las que la precedieron. La tecnociencia ha hecho realidad aquella manida sentencia de la "imaginación al poder" con que se inauguró en Europa una época en que se demostraría que las tecnocracias terminan adquiriendo una autonomía en que los medios se convierten en fines.

Tanto en las clásicas como en las modernas puede distinguirse entre biotecnologías rojas, aplicadas a seres humanos y vertebrados, verdes, relacionadas con el mundo vegetal, y blancas, vinculadas con productos industriales. Desde el punto de vista ético, lo relevante es su relación con los seres humanos y los cambios sociales. Lo que la contemporaneidad introduce es 
la capacidad técnica incrementada, el fundamento teórico y la aspiración totalizadora que promete bienestar y bendiciones que desafían la imaginación.

\section{PODER DE LAS BIOTECNOLOGÍAS. SOBERANÍA Y DISCIPLINA}

La posibilidad de intervención y manipulación plantea el tema del poder, central en toda discusión ética. "Conocimiento es poder" (el dictum baconiano) se convierte, en las biotecnologías, en realidad.

Distingamos, con Foucault, dos formas de poder (Foucault, 2005 ).

El poder de soberanía, basado en creencias, en acontecimientos fundacionales o los dichos de un líder carismático, liga a los dominados a través de una persona (real o mítica). La soberanía antecede a la sujeción y debe ser renovada mediante ritos (como las coronaciones de los reyes o las liturgias). Es un poder arbitrario no fundado en argumentación, deliberación o consenso. Deriva su autoridad de la tradición, el nacimiento o la pertenencia a un determinado grupo.

El segundo tipo de poder, llamado por Foucault poder disciplinario, tiene carácter prospectivo. Perfecciona relaciones de sujeción no basadas en el pasado, como el nacimiento, la tradición, el líder profético o la figura sacralizada. El poder se legitima por la eficacia de su ejercicio. No está sujeto a figuras humanas o rituales basados en una historia, sino a una racionalidad constructiva expresada en discursos que adquieren preeminencia o hegemonía. El poder no pertenece a personas sino a narrativas y discursos, que crean objetos de los cuales hablan. La fidelidad a tales discursos es fidelidad a la racionalidad que los crea y sustenta.

Todo poder, para ser eficaz, debe transformarse en autoridad. La autoridad disciplinaria depende de narrativas, cuya forma más perdurable e influyente es la escritura. Lo que no está escrito, no existe. Las reglamentaciones, las leyes, los instructivos, hasta las indicaciones de uso, son sus manifestaciones. Los autores de estas formas escritas de manifestación (o epifanía) del poder tienen diversa importancia según el producto. El trabajo científico y el libro, por ejemplo, son construcciones narrativas con nombres (autores) y ligan personas a textos en forma explícita.

En ocasiones, pueden confundirse el poder de soberanía y el poder de disciplina. Un escritor puede alcanzar ascendiente en una época o sobre un grupo de personas y hacer que sus textos tengan autoridad por su autoría y no por su contenido. El poder disciplinario, en estado puro, no depende de 
autores sino del contenido de "verdad" o eficacia. El artículo de periódico, el comunicado de prensa, la nota del "blog" tienen una relación más débil con el autor y su eficacia depende de la recepción. El texto de las instrucciones de uso tiene autoridad debido al poder disciplinario inherente y no al prestigio o importancia de su autor, en general anónimo.

La biotecnología moderna ejerce un poder de disciplina y no de soberanía. No se presenta como abracadabra hermético, sueño de alquimista o piedra filosofal cuyo secreto se manifiesta al iniciado sino como expresión de racionalidad científica que evoluciona hacia formas cada vez más perfectas de adecuación a deseos y necesidades humanas. Es el poder anónimo de las construcciones textuales que le dan visibilidad, prestigio y autoridad, y tienen el respaldo de la ciencia.

\section{CONSECUENCIAS SOCIALES DE LAS BIOTECNOLOGÍAS}

El poder de las biotecnologías contemporáneas se ejerce, en primer término, sobre la naturaleza. La natura naturans (la naturaleza no alterada) hábilmente usada en las biotecnologías clásicas, perturbada y manipulada en las modernas, se hace natura naturata. El método experimental no es solamente una forma ordenada de preguntar. Impone un ordenamiento forzado y forzoso. La experiencia de lo natural, que permitía a los antiguos intervenir sin alterar, se transforma en experimento, activo manipular sobre e interferir con lo natural. Experiencia y experimento son extremos diferentes del trato con lo natural. En un caso predomina la aceptación de límites y la simpatía, en otro la agresiva transformación manipuladora. El primero es un poder amistoso con lo natural, que en alemán podría llamarse Macht. El segundo es un poder que coacciona y domina, identificándose con la palabra alemana Gewalt. Si se quisiera un símil, el biotecnólogo clásico operaba con la naturaleza al realizar la hibridación, emplear la levadura o producir transformaciones materiales. El biotecnólogo moderno en cambio opera sobre la naturaleza o incluso contra ella, forzándola a realizaciones paranaturales o antinaturales. Estos términos no son peyorativos. Solamente indican algo inédito. En rigor, lo antinatural no existe pues el ingenio humano, del cual deriva la técnica, es fruto de la evolución natural. Pero muchos seres vivos creados por la industria transgénica no surgieron espontáneamente y el que existan es forzada generación de algo que pudo haber acontecido o de procesos que quizá no hubieran ocurrido. La naturaleza, construida imaginativamente por las ciencias, es hecha realidad de su operación. 
El poder se ejerce también sobre los seres humanos. La separación de éstos de la naturaleza es digna de crítica. Frente a la continuidad postulada por las ciencias biológicas, existe la inconmensurabilidad del pensamiento religioso, al menos el judeocristiano, según el cual los seres humanos son cualitativamente distintos de la naturaleza. Mas el ser humano de las ciencias es una creación artificial. Cada disciplina lo construye según principios distintos: el de la bioquímica no es el del derecho. El principio individualizador actúa diversamente según el tipo de poder (Lolas, 2005). Por ejemplo, como individuo se es responsable ante la ley, pero como especie se posee atributos comunes con otros seres vivos. El concepto de Hombre (combatido por algunas feministas basándose en la estructura superficial del lenguaje) es una creación de las ciencias y de los dispositivos de poder generados por los discursos. Por ejemplo, el dispositivo "PSI" formula lo humano en base a lo anímico, lo pulsional o lo relacional. En algunas de sus formas genera una unidad que en la "naturaleza" es imposible aislar: el individuo. Siempre se es, por ejemplo, hijo de un padre, hermano de un hermano, discípulo de un profesor, etc. Lo humano es relación y el individuo una ficción convertida en núcleo de decisión y acción, pero sin entidad propia (Christian $\&$ Haas, 1949). El cuerpo individual no necesariamente coincide con el sujeto y sabemos que se "habita" muchos cuerpos (el social, el dramático, el demostrativo, el del sufrimiento, etc.). Puede decirse que todos los dispositivos que genera el poder disciplinario remiten a metáforas: el ser vivo, la máquina, el algoritmo. Así, la fisiología del siglo XIX concibió los seres vivos como máquinas fisicoquímicas (Lolas, 1995). El psicoanálisis propuso, en algunas de sus versiones, un sistema nervioso conceptual basado en pulsiones y represiones. El organismo de la medicina moderna es una suma de guarismos y mediciones.

El poder disciplinario de las biotecnologías se ejerce sobre la naturaleza y sobre seres humanos constituidos por y para la mirada científica. El individuo, desde el punto de vista de la genómica, no es más que un agregado transitorio de atributos genéticos, modificado fenotípicamente según los entornos. Un riesgo del poder biogenómico es dejarse influir por los deseos o necesidades de individuos que afecten a toda la masa genética de la especie. Puede haber campañas eugenésicas basadas, por ejemplo, en atributos deseables para algunas culturas o en entelequias de sabor idealista (como la "raza aria"). Ha ocurrido muchas veces y en muchos países. Debe destacarse que las consecuencias sociales de las biotecnologías para "mejorar" personas, curar enfermedades o aumentar el bienestar deben considerar el poder 
sobre lo natural y lo artificial, y también el fundamento de ese poder. La "ciencia" es un producto cultural con distintos grados de consolidación y autoridad según el contexto. La misma noción de autoridad objetiva (o de los "hechos") está sujeta a transformaciones históricas. En ciencia, verdad es lo último descubierto o comprobado. Lo que no es dato es creencia.

Sin desconocer el poder y sus formas, el análisis ético debe separar lo factible, o realizable técnicamente, de lo legítimo, o fundamentable moralmente. Cuando se proponen moratorias o límites a la investigación científica (como en la conferencia de Asilomar o en declaraciones de advertencia) se las fundamenta en argumentaciones utilitarias. La precaución aconseja no arriesgar el futuro. La responsabilidad sugiere no ir más allá de lo seguro. Sin embargo, el riesgo, el peligro o la ignorancia no son suficientes para detener la investigación. Quienes trabajan profesionalmente en ciencia tienen la "verdad eficaz" como principio rector y no necesariamente la justicia o la beneficencia. Cualquier intento de imponer límites lo sienten algunos como coacción y limitación de la libertad humana y del progreso del conocimiento.

\section{DESCUBRIMIENTO E INVENCIÓN}

La distinción entre lo natural y lo artificial pierde parte de su atracción intuitiva y su valor emocional cuando se examina la interfaz entre biotecnología y poder.

Se difumina la distinción entre descubrimiento e invención. Si bien el cruzamiento de especies distintas (la mula, por ejemplo, cruce de asno y caballo) puede considerarse una invención, en realidad es descubrimiento de una posibilidad natural. Sin embargo, la creación de peces fosforescentes o cepas vegetales inéditas en la naturaleza es más invención que descubrimiento. Las biotecnologías modernas borran la distinción entre descubrimiento e invención y producen resultados paranaturales o no naturales en el sentido de no usar solamente potencialidades de la naturaleza, descubribles, sino potencialidades aún no actualizadas en ella, inventables.

En otro plano de reflexión ética, las biotecnologías directas o modernas incrementan posibilidades, eficacia y eficiencia. Más y mejores productos, más salud y mejor calidad de vida. Ello plantea la pregunta por el acceso a su goce y posesión. El aspecto económico ha determinado el desarrollo de todas las biotecnologías. Se han perfeccionado nociones como propiedad intelectual o de invención. El monopolio transitorio sobre los frutos de la in- 
vención o el descubrimiento, conocido como patentamiento, resguarda los privilegios económicos de los pioneros. Premia el ingenio y el esfuerzo. Por definición, renueva el mercado pues lo nuevo se presenta como lo mejor y lo mejor engendra necesidades. La pregunta moral es qué derecho tienen los desamparados y los pobres a gozar de los bienes desarrollados gracias a la inventiva desarrollada por el capital. Suele decirse que inventar consiste en transformar dinero (tangible) en ideas (intangibles). Aplicar consiste en transformar ideas (intangibles) en dinero (tangible). Este ciclo de la innovación tecnológica (dinero-ideas-dinero), ligado a la conciencia occidental, aparece en todas las épocas históricas, con diferentes énfasis y denominaciones. La justicia distributiva y el utilitarismo funcionan dentro de ciertos márgenes y no condicionan la emergencia o el desarrollo de las tecnologías.

Posibilidad de intervenir directamente, producción de bienes y servicios, impacto económico, eliminación de la diferencia entre descubrimiento e invención, modificación de lo conocido como natural son aspectos a considerar en un análisis ético.

\section{DILEMAS ÉTICOS EN LAS BIOTECNOLOGÍAS}

La licitud o ilicitud de intervenciones que parecen alterar la naturaleza es un tema central. Puede objetarse la manipulación de la vida por principios filosóficos o religiosos. Se discute si lo factible técnicamente es siempre legítimo moralmente. La aplicación de innovaciones a la vida humana siempre ha tenido una faz jánica, de dos aspectos. Por una parte, beneficios. Por otra, dificultades, riesgos, daños. Parece evidente, según el registro histórico de las tecnociencias, que nunca se ha detenido su progreso, solamente se lo ha retrasado o, a lo sumo, reorientado. Ha sido imposible impedir la difusión del conocimiento o su potencial abuso por parte de personas inescrupulosas. Las declaraciones de moratoria o prudencia son superadas por la idea de que el conocimiento es intrínsecamente bueno y su adquisición no debe prohibirse o impedirse. Cabe examinar cómo los beneficios pueden contrarrestar los posibles efectos negativos. En el pasado, la reflexión ética ha tenido un papel compensatorio. Retrospectivamente, frente a efectos no deseados, los humanistas determinan su impacto o su causa. Los nuevos desarrollos exigen una actitud anticipatoria, proactiva. Se trata de anticipar, prevenir o evitar lo adverso acompañando el progreso científico con reflexión moral que considere, como parte de su argumentación, los datos y las verdades instrumentales de las ciencias. La ética no puede ser más un monólo- 
go, férrea adhesión a doctrinas o derivación de normas a partir de creencias. La ética es hoy diálogo social, confrontación de intereses, fermento de convivencia. Cuando se indica diálogo se lo entiende entre personas, entre racionalidades, entre ideologías. La idea de responsabilidad, que implica dar cuenta de las propias acciones y responder por ellas, tiene que ver con la estructura dialógica del con-vivir. Las tecnologías son parte de esta trama de intereses sociales y no pueden practicarse en un vacío moral, pues no hay verdad pura o neutralidad valórica en los productos y las acciones. Ya abstenerse de opinar es adoptar una postura moralmente enjuiciable porque la única libertad que la humanidad no posee es la de dejar de ser libre para enfrentar opciones.

Un dilema es un problema cuya solución es otro problema. Los trasplantes de órganos resuelven un problema. Curan a las personas pero no las sanan, pues curar no es lo mismo que sanar. Quedan sujetas a control, con vidas limitadas. El problema se resuelve en forma eficaz, pero queda otro problema, quizá menos serio, pero problema al fin. Esto puede extenderse a otras situaciones creadas por las tecnologías, especialmente cuando sólo las tecnocracias evalúan sus logros y sus resultados. La autonomía de los sistemas tecnocráticos siempre ha constituido un riesgo. Al opacarse la relación con la necesidad que las técnicas originariamente satisfacen, priman los intereses de quienes aman más el arte que la humanidad. Así, técnicas con el declarado propósito de servir a las personas, como las de la medicina, pueden convertirse en un virtuosismo para especialistas, quienes llevan al límite sus posibilidades sin recordar necesariamente los orígenes y los fines iniciales. La filo-tecnía reemplaza a la filo-antropía y se convierte en auto-filía, amor propio de los tecnócratas, que al satisfacer sus propios fines pueden ignorar bienes sociales mayores o beneficios para toda la comunidad.

Aceptados los beneficios de la innovación tecnológica puede argüirse que debieran ser accesibles a todos los seres humanos según principios de equidad, necesidad o compasión. La lista de los dilemas éticos hace necesaria la conformación de una razón tecnocrática para "ilustración" de los expertos y los legos, de los dirigentes y los dirigidos, de los sabios y los ignorantes.

Reiteremos la faz jánica de todo progreso. Bueno en un sentido, malo en otro. Positivo para algunos, negativo para otros. Comunicable en ciertas formas, ocultable en otras. La ambigüedad y la vaguedad de las directrices morales, especialmente en la comunidad científica, son de regla. Si bien en algunos países se permiten algunas intervenciones y en otros se las prohíbe, no deja de reconocerse que el progreso de la ciencia no puede detenerse ya que ello pondría en peligro la hegemonía económica o política de las nacio- 
nes. Los beneficios de la biotecnología genómica, siempre riesgosos, son negados en algunos círculos por contravenir lo que parece ser ley natural.

Casi todos los avances técnicos se han acompañado de entusiasmos y temores. Los problemas técnicos nunca son solamente técnicos. También son problemas humanos, esto es, morales.

\section{ETAPAS DE LA INNOVACIÓN TECNOLÓGICA}

Las fases de la innovación biotecnológica en relación con la salud y el bienestar son conocidas. Primero, los iniciadores experimentan un optimismo tecnocrático. Luego, movilizan a inversionistas y potenciales usuarios, creando comunidades informales o formales de práctica. Se debe especificar ámbito de aplicación y contextos concretos de uso. Finalmente, la innovación es adoptada por la comunidad.

Este proceso es siempre valórico y el resultado puede considerarse exitoso solamente cuando la nueva tecnología se hace "invisible", esto es, se incorpora a los usos y costumbres de tal forma que se convierte en algo habitual, que no llama la atención y cuya presencia es imprescindible. El proceso decisivo es más social que técnico o técnico en el sentido de ingeniería social. Una innovación como la telefonía celular sería inútil si las personas no la adoptaran como algo natural y los aparatos no se hicieran parte de la vida diaria. La generación de organismos transgénicos se convierte poco a poco en algo universal y, aunque resistido en algunos sitios, se labra una posición de importancia por los atractivos económicos que supone (Lolas, 2006).

La "polifonía moral" que supone la existencia de muchos interesados (y por ende, infinitos intereses) se resuelve mediante el diálogo. Sin embargo, hay formas de diálogo que consisten en realidad en monólogos con espejo, en donde uno de los interlocutores busca en el otro solamente lo que le refleja o apoya. Esta postura "especular" contrasta con la postura "tolerante", que acepta la discrepancia, aunque sea en medida limitada. Las motivaciones para entrar al diálogo pueden ser diversas, y en general las nociones de "bien común" suelen frasearse en términos de "derechos" y "obligaciones", lo que hace surgir cisuras entre las personas. A veces esta distancia se hace infranqueable, pues en sostener unos sus derechos y otros apelar a deberes u obligaciones, nadie repara en que la supervivencia de todos no es materia sólo de derechos o sólo de obligaciones. Es materia de solidaridad y reciprocidad.

En cada etapa del proceso de innovación hay conflictos y dilemas éticos diferentes. La etapa inicial, por ejemplo, plantea problemas como la propie- 
dad intelectual, el plagio, la falsificación de informaciones. Las etapas siguientes plantean dilemas derivados del diferente valor que distintos actores y agentes sociales asignan a la innovación

\section{LA INGENIERÍA GENÉTICA Y SUS DESAFÍOS}

El empleo de la palabra ingeniería destaca, en castellano, el papel operativo o de intervención. Como biotecnología moderna es en realidad la más visible, toda vez que su expresa finalidad es la modificación del genoma.

Los dilemas éticos se refieren a las consecuencias sociales, a las posibilidades de intervención y a los efectos sobre la economía.

Entre las consecuencias sociales deben destacarse las relacionadas con la salud y el bienestar humanos (Lolas, 2003a). Por ejemplo, la llamada terapia génica intenta modificar el genoma en un sentido saludable, reemplazando genes defectuosos o predisponentes a enfermedades o atenuando sus efectos. Las expectativas, grandes al principio, se han visto reducidas por accidentes conocidos (caso Gelsinger) y por el factor de impredectibilidad de los métodos utilizados. El conocimiento detallado del genoma individual permite conocimiento sobre ascendientes y descendientes, susceptibilidad a dolencias o predisposiciones y así constituir motivo para estigmatizar o discriminar en los sistemas laborales y de cuidado de la salud.

Las posibilidades de intervención se relacionan con el interés de conocer la constitución genética de los individuos, con el fin de facilitar o hacer más precisa la intervención farmacológica, la susceptibilidad a enfermedades o las potencialidades individuales. La farmacogenómica busca medicamentos más adecuados al caso individual y reducir los efectos laterales de los existentes. Los estudios de genómica poblacional pueden producir "mapas" de poblaciones vulnerables o susceptibles.

Los efectos sobre la economía van desde la aceptación o rechazo de los alimentos transgénicos de origen vegetal o animal, el patentamiento de especies modificadas, el acceso a técnicas diagnósticas o terapéuticas, entre otros aspectos.

En cada una de estas áreas es posible identificar los dilemas éticos siempre que se respete el principio de una adecuada formulación. No se trata siempre ni solamente de choque entre principios canónicos como la beneficencia, la justicia o la autonomía. En un área que no solamente afecta individuos sino poblaciones en forma vertical (ascendientes y descendientes), también se plantea el problema ético de diagnosticar condiciones para las cuales no existe todavía curación o adecuada prevención. 
El ciudadano corriente suele no estar capacitado para valorar el impacto de las intervenciones sobre el genoma. Mucha de la información que adquiere viene tamizada por un interés periodístico que no se relaciona con su veracidad o precisión sino con el grado en que sorprende o espanta. De allí que sea necesario realizar periódicos estudios sobre el conocimiento real que las personas tienen de la ciencia en general y de la genómica en particular, pues las representaciones sociales son muy diversas y las tecnologías de la comunicación fácilmente desvían la atención hacia aspectos que los científicos no considerarían relevantes, pero que pueden incidir en la postura de aceptación o rechazo del público. Este aspecto, central en toda evaluación social de las biotecnologías (especialmente la genómica), debe acompañar al proceso de investigación y creación de conocimiento (Lolas, 2003b). En realidad, la moral dialógica y proactiva que precisa la ciencia como cultura y no simple artesanía supone interlocutores conscientes de sus capacidades, preparados para reconocer carencias y abiertos a considerar intereses amplios (Lolas, 2004, 2007; Lolas et al., 2004).

\section{REFERENCIAS}

Christian, Paul y Haas, Renate. 1949. Wesen und Formen der Bipersonalität. Stuttgart: Enke Verlag.

Foucault, Michel. 2005. El poder psiquiátrico. Buenos Aires: Fondo de Cultura Económica.

Lolas, Fernando. 1995. La perspectiva psicosomática en medicina. Santiago de Chile: Editorial Universitaria.

Lolas, Fernando. 2003a. "Genômica e bioética: o valor dâ ciencia na sociedade". En Garrafa, Volnei \& Pessini, Leo (organizadores), Bioética: Poder e injustica. Edicoes Loyola \& Centro Universitario Sao Camilo, Sao Paulo, Brasil, Cap. 11, pp. 129-136.

Lolas, Fernando. 2003b. "La clonación de humanos: aproximación ética". En Fundación Fernando Fueyo Laneri, Derecho, bioética y genoma humano. Editorial Jurídica de Chile, pp. 145-156.

Lolas, Fernando. 2004. "Genómica y bioética: culturas epistémicas y construcción social”. En Brena, Ingrid. y Díaz Muller, Luis T. (coordinadores), Segundas Jornadas sobre Globalización y Derechos Humanos: Bioética y biotecnología. Instituto de Investigaciones Jurídicas, Universidad Nacional Autónoma de México, México, pp. 71-90.

Lolas, Fernando. 2005 "El discurso disciplinario: Una nota sobre sus atributos". En Harvey, Ana María (compiladora), En torno al discurso. Contribuciones de América Latina. Santiago de Chile: Ediciones Universidad Católica de Chile, pp. 329-338. 
Lolas, Fernando (editor). 2006 Ética e innovación tecnológica. Santiago, Chile: Centro Interdisciplinario de Estudios en Bioética, Universidad de Chile.

Lolas, Fernando. 2007. "De genómica e gen-ética: Bionómica e Bioética". En Romeo- Casabona, C. \& Freire de Sá, M. (coordenadotes), Desafíos Jurídicos da Biotecnología. Mandamentos Editora, Belo Horizonte, Brasil, pp. 65-76.

Lolas, Fernando; Rodríguez, Eduardo y Valdebenito, Carolina. 2004. "El proyecto del genoma en la literatura biomédica latinoamericana de cuatro países". Acta Bioethica (OPS, Santiago de Chile), 10: 167-180.

פख़ 